\title{
ROBOTIC-ASSISTED INFERIOR VENA CAVA FILTER RETRIEVAL
}

\author{
Shahin Owji; Tony Lu, M.D.; Thomas M. Loh, M.D.; Adeline Schwein, M.D.; Alan B. Lumsden, M.D.; Jean \\ Bismuth, M.D. \\ Houston Methodist DeBakey Heart \& Vascular Center, Houston Methodist Hospital, Houston, Texas
}

\begin{abstract}
Although anticoagulation remains the mainstay of therapy for patients with venous thromboembolism, guidelines recommend the use of inferior vena cava (IVC) filters in those who fail anticoagulation or have contraindications to its use. Short-term use of filters has proven effective in reducing the rate of pulmonary embolism. However, their extended use is associated with a variety of complications such as thrombosis, filter migration, or caval perforation, thus making a case for timely filter retrieval.

This is the case of a 68-year-old female with a history of chronic oral anticoagulation use for multiple deep venous thrombi (DVT) and pulmonary emboli (PE) who required cervical and thoracic spinal intervention for spondylosis and foramina stenosis. Given her increased risk of recurrent DVT and PE perioperatively, we elected to place a Cook Celect ${ }^{\mathrm{TM}}$ IVC filter (Cook Medical, Bloomington, IN) after oral anticoagulation was stopped for the procedure. Her treatment course was prolonged due to wound-healing complications. We elected to use the Magellan Robotic Catheter System (Hansen Medical, Mountain View, CA) for filter retrieval when she presented 6 months later with caval perforation from the filter struts. With its ease of use, superior mechanical stability, and maneuverability, robot-assisted IVC filter retrieval may be a safer and more reliable substitute for traditional navigation techniques when presented with challenging filter retrievals.
\end{abstract}

\section{Introduction}

Approximately 49,000 inferior vena cava (IVC) filters are placed annually in the United States, and this figure continues to grow. ${ }^{1}$ As the implantation of filters increases, so has their associated complications. Long-term indwelling filters have been associated with component failure, migration, and perforation that sometimes necessitates open retrieval in affected patients. ${ }^{2-6}$ This has prompted the U.S. Food and Drug Administration to recommend close follow-up of patients with indwelling filters and prompt removal of the devices after their acute indication has been resolved. ${ }^{7}$ Adequate follow-up remains the Achilles heel of filter retrieval, with some series showing baseline rates as low as $8 \%{ }^{8,9}$ Standard endovascular retrieval using catheter and snare techniques remains the mainstay of therapy, with reports showing technical success in only $73.2 \%$ of cases. ${ }^{4}$ More aggressive techniques using multiple access sites, lasers, and bronchial forceps have demonstrated improved retrieval rates above $90 \%$ but are associated with increased complications. ${ }^{2-4}$ We present an alternative technique for IVC filter retrieval using the Magellan Robotic System (Hansen Medical, Mountain View, CA) that may be beneficial in difficult cases.

\section{Clinical Case}

This is the case of a 68-year-old female patient with a history of protein $C$ deficiency who was managed on Coumadin after multiple episodes of deep vein thrombosis (DVT) and pulmonary embolism (PE). The patient had been event-free since starting anticoagulation but was recently diagnosed with C7-T1 spondylosis with bilateral foraminal stenosis, which necessitated bilateral hemilaminotomies and foraminotomies. Her Coumadin was suspended and a Celect ${ }^{\mathrm{TM}}$ IVC filter (Cook Medical, Bloomington, IN) was placed. After her surgery, she experienced several surgical site infections requiring multiple reoperations and eventual muscle flap coverage. Nearly 6 months later she was back in the outpatient clinic requesting IVC filter retrieval due to radiographic evidence of caval perforation from the filter struts.

During the retrieval, the patient's right internal jugular vein was punctured under ultrasound guidance with a micropuncture system and upsized to a 9F sheath over a Bentson wire (Cook Medical, Bloomington, IN). A venogram was performed and demonstrated no visible thrombus within the filter but showed the struts perforating the caval wall (Figure $1 \mathrm{~A}$ ). A 90-cm 9F robotic sheath was advanced into the IVC and situated just cephalad to the IVC filter with the Magellan Robotic System (Figure 1 B). The CloverSnare ${ }^{\circledR}$ 4-Loop Vascular Retriever (Cook Medical) was then advanced through the robotic sheath cephalad to the filter (Figure $1 \mathrm{C}$ ) to capture the hook and retrieve the filter (Figure $1 \mathrm{D}$ ). Upon removal, the filter was noted to be intact with no fractures. Neither signs of thrombosis nor residual portions of the IVC filter were observed with a completion angiography (Figure $1 \mathrm{E})$. The robotic sheath and catheter were then removed, and pressure was held for 5 minutes on the insertion site. The skin was closed with DERMABOND® (Ethicon US, Cincinnati, $\mathrm{OH}$ ), and the patient was discharged home the same day without complication.

\section{Discussion}

More than 900,000 Americans, or 1 to 2 per 1,000, are affected each year by venous thromboembolism (VTE). Of these, between 60,000 and 100,000 die as a result. ${ }^{5}$ Although anticoagulation is the accepted standard treatment for VTE, in some cases medical therapy has to be permanently or temporary stopped. ${ }^{10}$ Our patient tolerated Coumadin well but had to stop secondary to her spinal surgery. Because of her high risk of VTE recurrence, we elected to place a temporary IVC filter for perioperative VTE protection. ${ }^{11-13}$

Safety and timing of filter retrieval has been an area of growing concern in the medical literature. A wide array of pathophysiological and social obstacles are faced by physicians in these cases, negatively impacting filter retrieval rates. ${ }^{14}$ In a study of 231 filter 

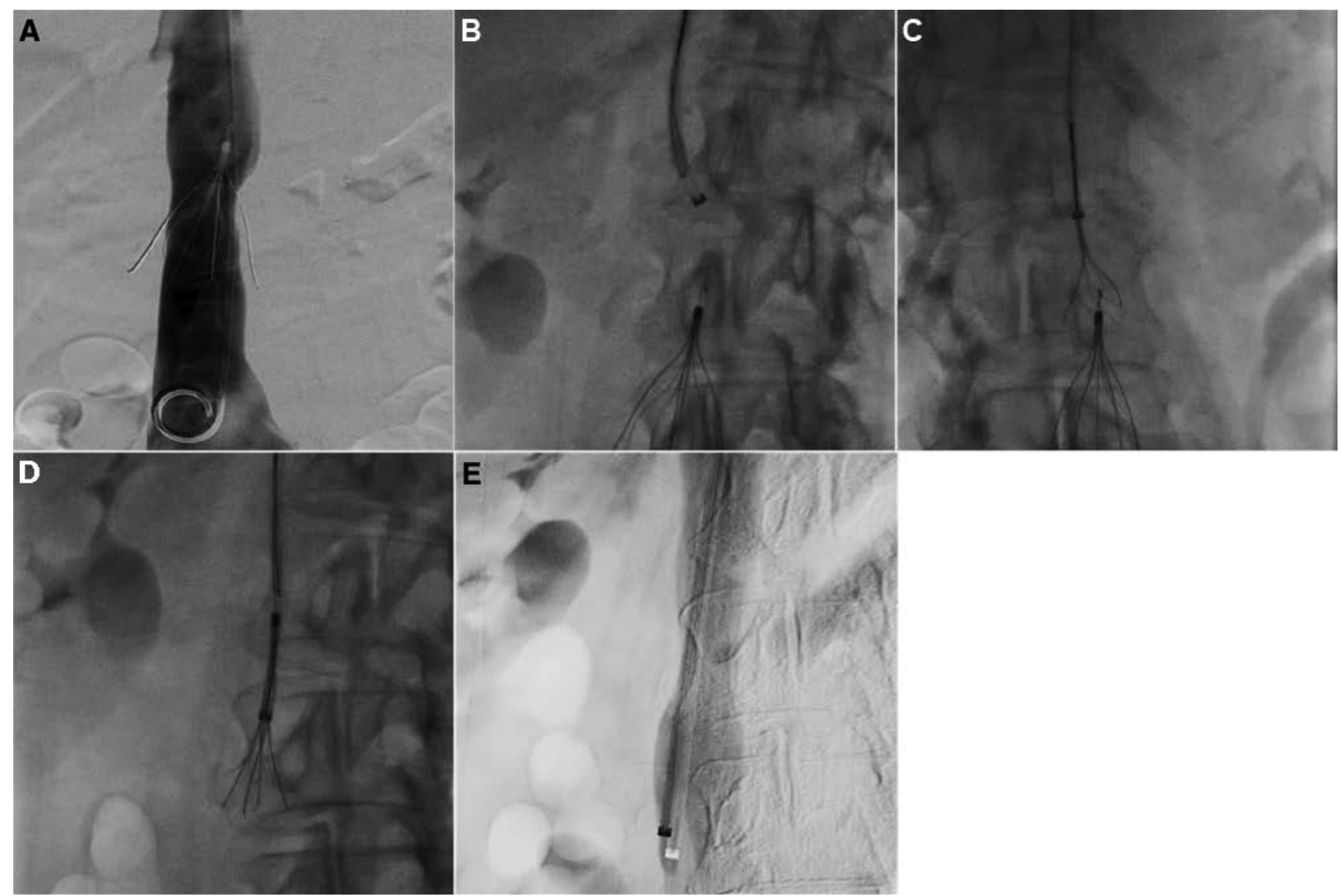

Figure 1. (A) A venogram demonstrates no thrombus within the filter. (B) A 9F sheath is guided with the Magellan Robotic System proximal to the inferior vena cava (IVC) filter. (C) The CloverSnare 4-Loop Vascular Retriever is advanced through the sheath and situated above the filter. (D) The filter hook is captured and the filter is delivered through the sheath. (E) A completion angiography displays no signs of thrombosis or residual portions of the filter within the IVC.

retrieval attempts via the standard technique, only $73.2 \%$ were successful, and one patient developed severe IVC stenosis due to the filter legs coapting. ${ }^{4}$ In other series, the retrieval rate has been estimated to be as low as $29 \%$ to $60 \%$, with the primary challenges being penetration of the caval wall, fractures, migration, and tilting. $9,15,16$

These suboptimal retrieval rates underscore the inadequacy of routine retrieval and have driven physicians to pursue more advanced approaches, such as stiff-wire displacement, dual-access, balloon displacement, realignment, and the "sling" technique. Endovascular dissection to directly release an embedded hook or penetrating strut with bronchoscopy forceps has also been described as a last-ditch effort. ${ }^{17}$ These advanced techniques increase the probability of successful retrieval to more than $90 \%$ but are also associated with significantly higher complication rates $(5.3 \%$ vs. $0.4 \%) .{ }^{4}$ Open surgical approaches are yet another possibility but can lead to increased morbidity and prolong hospitalization secondary to the need for laparotomy and caval reconstruction. ${ }^{18}$

The high risk of complications from filter retrieval often dissuades both patients and physicians from proceeding. Yet, leaving the filter in place can lead to long-term complications such as DVT, caval penetration, and filter migration, making future attempts more challenging. ${ }^{19}$ This conundrum has led to increased efforts to create an effective monitoring and tracking system to systematical- ly follow those with temporary filters and evaluate their candidacy for retrieval. ${ }^{8,20}$

With this case, we present an innovative alternative to other advanced filter retrieval techniques with use of the Magellan Robotic System. The robotic sheath was used in this patient to navigate to the filter and position the snare over the hook, thus providing a stable platform for retrieval. Compared to conventional endovascular devices, the system's steerability and flexibility allow for greater control in narrow vessel lumens and complex situations. The Magellan's navigational capabilities also can be paired with other advanced techniques to decrease procedural complexity and improve overall retrieval rates.

\section{Conclusion}

Although IVC filter retrieval is possible with conventional techniques, the Magellan Robotic System has the potential to improve retrieval rates and decrease procedural complications through its precision and stability.

Conflict of Interest Disclosure: The authors have completed and submitted the Methodist DeBakey Cardiovascular Journal Conflict of Interest Statement and none were reported.

Keywords: inferior vena cava filter, Robotic Catheter System, IVC retrieval, venous thromboembolism, anticoagulation 


\section{References}

1. Patel SH, Patel R. Inferior vena cava filters for recurrent thrombosis: current evidence. Tex Heart Inst J. 2007;34(2):187-94.

2. Chou EL, Sgroi MD, Fujitani RM, Kabutey NK. Complex hybrid suprarenal inferior vena cava filter retrieval. Ann Vasc Surg. 2015 Jan;29(1):125.e19-22.

3. Doody O, Given M, Kavnoudias H, Street M, Thomson K, Lyon S. Initial experience in 115 patients with the retrievable Cook Celect vena cava filter. J Med Imaging Radiat Oncol. 2009 Feb 1;53(1):64-8.

4. Al-Hakim R, Kee ST, Olinger K, Lee EW, Moriarty JM, McWilliams JP. Inferior vena cava filter retrieval: effectiveness and complications of routine and advanced techniques. J Vasc Interv Radiol JVIR. 2014 Jun;25(6):933-9; quiz 940.

5. Beckman MG, Hooper WC, Critchley SE, Ortel TL. Venous thromboembolism. Am J Prev Med. 2010 Apr 1;38(4):S495501.

6. Kassi M, Lopez J, Barker C, Trerotola S, Kleiman N, Kurrelmeyer K. Case report: It wasn't cupid: multimodality imaging of inferior vena cava filter fracture with strut migration to the interventricular septum. Methodist DeBakey Cardiovasc J. 2014 Sep;10(3):198200.

7. U.S. Food and Drug Administration [Internet]. Silver Springs, MD: U.S. Food and Drug Administration; c2016. Removing Retrievable Inferior Vena Cava Filters: FDA Safety Communication; 2014 May 6 [cited 2016 Dec 7]. Available from: http://www.fda. gov/MedicalDevices/Safety/AlertsandNotices/ucm396377.htm

8. Sutphin PD, Reis SP, McKune A, Ravanzo M, Kalva SP, Pillai AK. Improving inferior vena cava filter retrieval rates with the define, measure, analyze, improve, control methodology. J Vasc Interv Radiol. 2015 Apr;26(4):491-8.e1.

9. Sarosiek S, Crowther M, Sloan JM. Indications, complications, and management of inferior vena cava filters: the experience in 952 patients at an academic hospital with a level I trauma center. JAMA Intern Med. 2013 Apr 8;173(7):513-7.

10. Kearon C, Akl EA, Comerota AJ, et al.; American College of Chest Physicians. Antithrombotic therapy for VTE disease: Antithrombotic Therapy and Prevention of Thrombosis, 9th ed:
American College of Chest Physicians Evidence-Based Clinical Practice Guidelines. Chest. 2012 Feb;141(2 Suppl):e419S-94S.

11. Ozturk C, Ganiyusufoglu K, Alanay A, Aydogan M, Onat L, Hamzaoglu A. Efficacy of prophylactic placement of inferior vena cava filter in patients undergoing spinal surgery: Spine (Phila $\mathrm{Pa}$ 1976). 2010 Sep 15;35(20):1893-6.

12. Rosner MK, Kuklo TR, Tawk R, Moquin R, Ondra SL. Prophylactic placement of an inferior vena cava filter in high-risk patients undergoing spinal reconstruction. Neurosurg Focus. 2004 Oct 15;17(4):E6.

13. Leon L, Rodriguez H, Tawk RG, Ondra SL, Labropoulos N, Morasch MD. The prophylactic use of inferior vena cava filters in patients undergoing high-risk spinal surgery. Ann Vasc Surg. 2005 May;19(3):442-7.

14. Siracuse JJ, Al Bazroon A, Gill HL, et al. Risk factors of nonretrieval of retrievable inferior vena cava filters. Ann Vasc Surg. 2015 Feb;29(2):318-21.

15. Nazzal M, Chan E, Nazzal M, et al. Complications related to inferior vena cava filters: a single-center experience. Ann Vasc Surg. 2010 May;24(4):480-6.

16. Thomas JH, Cornell KM, Siegel EL, Sparks C, Rosenthal SJ. Vena caval occlusion after bird's nest filter placement. Am J Surg. 1998 Dec;176(6):598-600.

17. Stavropoulos SW, Ge BH, Mondschein JI, Shlansky-Goldberg RD, Sudheendra D, Trerotola SO. Retrieval of Tip-embedded Inferior Vena Cava Filters by Using the Endobronchial Forceps Technique: Experience at a Single Institution. Radiology. 2015 Jun;275(3):900-7.

18. Jehangir A, Rettew A, Shaikh B, et al. IVC filter perforation through the duodenum found after years of abdominal pain. Am J Case Rep. 2015 May 16;16:292-5.

19. Chow FC, Chan YC, Cheung GC, Cheng SW. Mid- and longterm outcome of patients with permanent inferior vena cava filters: a single center review. Ann Vasc Surg. 2015 Jul;29(5):98594.

20. Goei AD, Josephs SC, Kinney TB, Ray CE Jr, Sacks D. Improving the Tracking and Removal of Retrievable Inferior Vena Cava Filters. Semin Interv Radiol. 2011 Mar;28(1):118-27. 